\title{
In situ precipitation: a novel approach for preparation of iron-oxide magnetoliposomes
}

This article was published in the following Dove Press journal:

International Journal of Nanomedicine

23 May 2014

Number of times this article has been viewed

\author{
Shudong Xia' \\ Peng $\mathrm{Li}^{\prime}$ \\ Qiang Chen' \\ Malik Armah ${ }^{2}$ \\ Xiaoying Ying ${ }^{3}$ \\ Jian $\mathrm{Wu}^{4}$ \\ Jiangtao $\mathrm{Lai}^{5}$ \\ 'Yiwu Affiliated Hospital, College \\ of Medicine, ${ }^{2}$ College of Medicine, \\ ${ }^{3}$ College of Pharmacy, ${ }^{4}$ College of \\ Nanotechnology, ${ }^{5}$ First Affiliated \\ Hospital, College of Medicine, \\ Zhejiang University, Hangzhou, \\ People's Republic of China
}

Correspondence: Jiangtao Lai Department of Cardiology, The First Affiliated Hospital, College of Medicine, Zhejiang University, Hangzhou, People's Republic of China

$\mathrm{Tel}+8613989897610$

Fax +86 57I87236707

Email shystone@126.com
Background: Conventional methods of preparing magnetoliposomes are complicated and inefficient. A novel approach for magnetoliposomes preparation was investigated in the study reported here.

Methods: $\mathrm{FeCl}_{3} / \mathrm{FeCl}_{2}$ solutions were hydrated with lipid films to obtain liposome-encapsulated iron ions by ultrasonic dispersion. Non-encapsulated iron ions were removed by dialysis. $\mathrm{NH}_{3} \cdot \mathrm{H}_{2} \mathrm{O}$ was added to the system to adjust the $\mathrm{pH}$ to a critical value. Four different systems were prepared. Each was incubated at a different temperature for a different length of time to facilitate the permeation of $\mathrm{NH}_{3} \cdot \mathrm{H}_{2} \mathrm{O}$ into the inner phase of the liposomes and the in situ formation of magnetic iron-oxide cores in the liposomes. Single-factor analysis and orthogonal-design experiments were applied to determinate the effects of alkalization $\mathrm{pH}$, temperature, duration, and initial Fe concentration on encapsulation efficiency and drug loading.

Results: The magnetoliposomes prepared by in situ precipitation had an average particle size of $168 \pm 14 \mathrm{~nm}$, zeta potential of $-26.2 \pm 1.9 \mathrm{mV}$ and polydispersity index of $0.23 \pm 0.06$. The ironoxide cores were confirmed as $\mathrm{Fe}_{3} \mathrm{O}_{4}$ by $\mathrm{X}$-ray diffraction and demonstrated a superparamagnetic response. Encapsulation efficiency ranged from $3 \%$ to $22 \%$, while drug loading ranged from 0.2 to $1.58 \mathrm{~mol} \mathrm{Fe} / \mathrm{mol}$ lipid. The optimal conditions for in situ precipitation were found to be an alkalization $\mathrm{pH}$ of 12 , temperature of $60^{\circ} \mathrm{C}$, time of 60 minutes, and initial $\mathrm{Fe}$ concentration of $100 \mathrm{mM} \mathrm{Fe}^{3+}+50 \mathrm{mM} \mathrm{Fe}^{2+}$.

Conclusion: In situ precipitation could be a simple and efficient approach for the preparation of iron-oxide magnetoliposomes.

Keywords: magnetoliposomes, in situ precipitation, iron oxide, alkalization, permeability

\section{Introduction}

Magnetoliposomes have been widely used as targeted drug-delivery systems and highly efficient magnetic resonance imaging contrast agents. These biocompatible systems also offer the possibilities for targeting and delivering therapeutic agents for "theragnostics", a therapy and diagnosis strategy. ${ }^{1-3}$

Current ways of preparing magnetoliposomes usually involve two steps: 1) magnetofluid is prepared by surface modification of iron-oxide nanocrystals, usually requiring several cycles of heating, precipitation, and purification, and 2) magnetofluid is encapsulated into liposomes to form magnetoliposomes. However, this conventional approach has limitations, including the fact that the magnetofluid preparation procedure is very complex and laborious, and the encapsulation efficiency (EE) and drugloading capacity of magnetofluid in liposomes are very low due to the instability of magnetofluid. The drug loading of magnetoliposomes reported so far has ranged from 
0.1 to $1.67 \mathrm{~mol} \mathrm{Fe} / \mathrm{mol}$ lipid. However, magnetoliposomes with a high drug-loading capacity $(>0.5 \mathrm{~mol} \mathrm{Fe} / \mathrm{mol}$ lipid $)$ were unstable in those studies. ${ }^{4-6}$

In this study, we developed a novel approach to magnetoliposome preparation that may be applied in targeted drug-delivery systems and which involves two steps. Step 1 involved hydrating $\mathrm{FeCl}_{3} / \mathrm{FeCl}_{2}$ solutions with lipid films to obtain liposomes by ultrasonic dispersion. Non-encapsulated $\mathrm{FeCl}_{3} / \mathrm{FeCl}_{2}$ was removed by dialysis. In Step 2, the liposomes were alkalized by adding $\mathrm{NH}_{3}$ to raise the $\mathrm{pH}$ to a critical value and incubated at a certain temperature for a certain time. After centrifugation and dialysis, the purified magnetoliposomes were obtained.

The novel methodology is based on the principle of the different permeability of $\mathrm{NH}_{3}$ and $\mathrm{Fe}^{3+} / \mathrm{Fe}^{2+}$ into the lipid bilayer of liposomes. As a small molecule, $\mathrm{NH}_{3}$ has great permeability into lipid bilayer, with a permeability coefficient of nearly $10^{-2} \mathrm{~cm} / \mathrm{s},{ }^{7}$ while, as multivalent cations, $\mathrm{Fe}^{3+}$ and $\mathrm{Fe}^{2+}$ have poorer permeability into the lipid bilayer, with a permeability coefficient of about $10^{-13} \mathrm{~cm} / \mathrm{s}^{8-10}$ Thus, when $\mathrm{NH}_{3}$ is added to the solution of encapsulated $\mathrm{Fe}^{3+} / \mathrm{Fe}^{2+}$ liposomes, $\mathrm{NH}_{3}$ diffuses into the liposomes rapidly, but only a limited amount of $\mathrm{Fe}^{2+} / \mathrm{Fe}^{3+}$ leaks out from the liposomes. When the solution is heated, the difference is more significant. $\mathrm{As}_{3} \mathrm{NH}_{3}$ diffuses into the liposomes, the $\mathrm{pH}$ value of the internal phase increases and $\mathrm{Fe}^{3+} / \mathrm{Fe}^{2+}$ undergo a hydrolytic reaction $\left(2 \mathrm{Fe}^{3+}+\mathrm{Fe}^{2+}+\right.$ $\left.8 \mathrm{NH}_{3} \cdot \mathrm{H}_{2} \mathrm{O}=\mathrm{Fe}_{3} \mathrm{O}_{4}+8 \mathrm{NH}_{4}^{+}+4 \mathrm{H}_{2} \mathrm{O}\right)$.

In this way, the magnetic cores of the magnetoliposomes were formed in situ.

\section{Materials and methods Materials}

The components of liposomes - 1, 2-dipalmitoyl-sn-glycero3-phosphocholine (DPPC; molecular weight [MW] 734), cholesterol (CH, MW 387), and 1, 2-distearoyl-sn-glycero3-phosphoethanolamine-N-poly(ethylene glycol)2000 (PEG2000DSPE, MW 2, 805) - were purchased from Avanti Polar Lipids (Alabaster, AL, USA). $\mathrm{FeCl}_{2} \cdot 4 \mathrm{H}_{2} \mathrm{O}$ (MW 201) and $\mathrm{FeCl}_{3} \cdot 6 \mathrm{H}_{2} \mathrm{O}(\mathrm{MW} 273.5$ ) were used to prepare the solutions of $\mathrm{FeCl}_{2}$ and $\mathrm{FeCl}_{3}$ at various concentrations.

\section{Preparation of magnetoliposomes}

\section{Preparation of liposome-encapsulated iron ions}

$\mathrm{FeCl}_{3} / \mathrm{FeCl}_{2}$ solutions were hydrated with lipid films to obtain liposomes by ultrasonic dispersion. Non-encapsulated $\mathrm{FeCl}_{3} /$ $\mathrm{FeCl}_{2}$ was removed by dialysis.

In detail, lipid mixtures of DPPC, $\mathrm{CH}$, and PEG2000DSPE in 55:40:5 mole ratios were dissolved in chloroform in a round-bottom flask and formed into a thin film by removing chloroform under a nitrogen stream followed by evaporation under vacuum for 12 hours. Dry films were hydrated with various concentrations of $\mathrm{FeCl}_{3} / \mathrm{FeCl}_{2}$ (mole ratios $=2: 1$ ) solutions to give a lipid concentration of $20 \mathrm{mM}$. The mixtures were then sonicated gently in a Transonic Digitals Bath Sonifier (Elma Hans Schmidbauer GmbH \& Co. KG, Singen, Germany) within a $50^{\circ} \mathrm{C}$ water bath until the film totally detached from the flask (about 60 minutes). The mixtures were downsized by further aggravated sonication using a $600 \mathrm{~W}$ ultrasound probe (Kejie Co. Ltd, Nanjing, People's Republic of China) treated in a $50^{\circ} \mathrm{C}$ water bath for 2 minutes (work time 2 seconds, gap time 3 seconds). Then the mixtures were dialyzed overnight at room temperature in a 100,000-molecular-weight-cutoff dialysis bag against distilled water to remove non-encapsulated $\mathrm{FeCl}_{3} / \mathrm{FeCl}_{2}$. Thus, we obtained liposome-encapsulated iron ions.

\section{Alkalization of liposome-encapsulated iron ions}

The liposomes were alkalized by adding $\mathrm{NH}_{3}$ to raise the $\mathrm{pH}$ to a critical value and then incubated at a certain temperature for a certain time. The $\mathrm{pH}$ value was chosen from 10 to 13 , because a lower $\mathrm{pH}$ value would be unable to alkalize iron ions and a higher $\mathrm{pH}$ value would accelerate the hydrolysis of phospholipids incorrectly. After centrifugation and dialysis, the purified magnetoliposomes were obtained.

In detail, the $\mathrm{pH}$ values of the liposome-encapsulated iron ions were measured using a $\mathrm{pH}$ meter. To adjust the $\mathrm{pH}$ to the target value $(\mathrm{pH} 10,11,12$, or 13$), 1 \mathrm{M} \mathrm{NH}_{3} \cdot \mathrm{H}_{2} \mathrm{O}$ was added to the liposome solutions. Following this, the mixtures were incubated at the target temperature $\left(30^{\circ} \mathrm{C}\right.$, $40^{\circ} \mathrm{C}, 50^{\circ} \mathrm{C}$, and $60^{\circ} \mathrm{C}$ ) in a water bath for a certain time $(15,30,60$, and 120 minutes) with vigorous stirring. After that, the black sediment was removed by centrifugation for 15 minutes at $4,000 \times g$, and the brown supernatant was collected. The supernatant was placed in a 10,000molecular-weight-cutoff dialysis bag suspended in a 50-fold volume of distilled water and stirred for 24 hours to remove the $\mathrm{NH}_{3} \cdot \mathrm{H}_{2} \mathrm{O}$. Thus, we obtained magnetoliposomes with iron-oxide cores.

\section{Characterization of magnetoliposomes Characterization of the iron-oxide cores}

Prior to characterization of the iron-oxide cores by X-ray diffraction (using a D8 Advance; Bruker, Billerica, MA, USA), $10 \mathrm{~mL}$ of magnetoliposomes was ruptured in a tenfold volume excess of ethanol. The mixture was centrifuged after which the liquid that had pooled at the top was poured off without 
disturbing the sediment at the bottom. The sediment was dried under vacuum at room temperature for 24 hours. The X-ray patterns were taken using an X'Pert Powder system (PANalytical, Almelo, the Netherlands). The divergence slit was $1^{\circ}$ and the receiving slit was $0.15^{\circ}$. The starting and final $2 \theta$ angles were $20^{\circ}$ and $80^{\circ}$, respectively. The step size was $0.05^{\circ} 2 \theta$ and the measuring time was 3 seconds per step. The result was compared with the Joint Committee on Powder Diffraction Standards powder-diffraction file card for iron oxide.

The magnetization curves of the iron-oxide cores were determined using a Model 7410 Vibrating Sample Magnetometer (Lake Shore Cryotronics, Westerville, OH, USA).

\section{Liposome size and morphology}

The mean particle size and particle size distribution of the magnetoliposomes were determined by dynamic light scattering at $25^{\circ} \mathrm{C}$ with a Zetasizer Nano (Malvern Instruments, Malvern, UK). To measure the particle size distribution of the dispersion, a polydispersity index ranging from 0.0 for an entirely monodisperse sample to 1.0 for a polydisperse sample was used.

Liposome morphology was studied by transmission electron microscopy (TEM) with a JEM-1200EX microscope (JEOL, Tokyo, Japan) operated at an acceleration voltage of $80 \mathrm{kV}$. The liposome sample was first diluted in distilled water and then mixed with phosphotungstic acid in a $1: 1$ volume ratio. The sample solutions were then deposited onto negatively charged copper grids that had been pre-coated with carbon.

\section{Determination of EE}

The initial concentration of iron ions added to the system was recorded as $\mathrm{Fe}_{\mathrm{a}}$. The concentration of the iron ions entrapped in the liposomes before alkalization was recorded as $\mathrm{Fe}_{\mathrm{b}}$. To measure $\mathrm{Fe}_{\mathrm{b}}, 0.1 \mathrm{~mL}$ of the liposomes was ruptured before alkalization by $0.9 \mathrm{~mL}$ of ethanol, and the concentration of the iron ions was measured by atomic absorption spectroscopy (3100 Atomic Absorption Spectrometer; PerkinElmer, Waltham, MA, USA).

The total amount of iron in the liposomes after alkalization was determined based on the concentration of iron ions. After alkalization, $0.1 \mathrm{~mL}$ of liposomes was ruptured by $0.9 \mathrm{~mL}$ of ethanol, then $9 \mathrm{~mL}$ of concentrated $\mathrm{HCl}(37 \%)$ was added to the samples to ionize the ironoxide crystal cores. The total iron-ion concentration of the mixture was measured by atomic absorption spectroscopy and recorded as $\mathrm{Fe}(\mathrm{t})$.

As some liposomes may not have been totally alkalized, they may have contained free iron ions. To determine the concentration of the free iron ions, after alkalization, $0.1 \mathrm{~mL}$ of liposomes was ruptured by $0.9 \mathrm{~mL}$ ethanol. The mixture was centrifuged at 3,000 rpm for 5 minutes. Thus, the iron-oxide cores would settle on the bottom, while the free iron ions would remain in the upper layer liquid. Then, $0.5 \mathrm{~mL}$ of the upper layer liquid was taken to determine the iron-ion concentration by adding $4.5 \mathrm{~mL}$ concentrated $\mathrm{HCl}(37 \%)$ and measurement by atomic absorption spectroscopy. It was recorded as $\mathrm{Fe}(\mathrm{f})$. The true amount of iron-oxide core - Fe(c) - was calculated by $\mathrm{Fe}(\mathrm{c})=\mathrm{Fe}(\mathrm{t})-\mathrm{Fe}(\mathrm{f})$. The $\mathrm{EE}$ of iron was expressed as $\mathrm{EE} \%=\mathrm{Fe}(\mathrm{c}) / \mathrm{Fe}_{\mathrm{a}}=\mathrm{Fe}(\mathrm{t})-\mathrm{Fe}(\mathrm{f}) / \mathrm{Fe}_{\mathrm{a}}$.

\section{Determination of drug loading}

Drug loading was expressed as the amount of encapsulated iron (mol) per mol of phospholipid. Drug loading $=\mathrm{Fe}(\mathrm{c})$ $(\mathrm{mM})$ /lipid content $(\mathrm{mM})$. The lipid content of the magnetoliposomes was determined based on the DPPC concentration, as measured by high-performance liquid chromatography (HPLC). The HPLC system consisted of a Waters 600 Solvent Delivery System (Waters Corporation, Milford, MA, USA), a Waters 712 WISP Autoinjector, a column heater, PerkinElmer Nelson Model 610 data acquisition system (PE Nelson System Inc., San Jose, CA, USA), an Astec $250 \times 4.6 \mathrm{~mm}$ diol-bonded phase column (Sigma-Aldrich, St Louis, MO, USA), and an evaporative light scattering detector (SEDEX ELSD; SEDERE, Alfortville, France). The mobile phase consisted of chloroform, methanol, and water at a volume ratio of $65: 25: 4$. A $50 \mu \mathrm{L}$ aliquot of the sample was diluted to $10 \mathrm{~mL}$ with chloroform:methanol (85:15, volume/volume) and injected into the HPLC system. The sample was prepared in duplicate and analyzed at a flow rate of $1.3-1.5 \mathrm{~mL} / \mathrm{minute}$. The amount of DPPC in the formulation was quantitatively determined using external standards.

\section{Effects of alkalization $\mathrm{pH}$, temperature, duration, and initial Fe concentration}

The effects of alkalization $\mathrm{pH}$, temperature, duration, and initial iron-ion concentration on the EE and drug loading of magnetoliposomes were determined by singlefactor analysis. Specifically, four levels of alkalization $\mathrm{pH}$ $\left(\mathrm{pH}_{1}=13, \mathrm{pH}_{2}=12, \mathrm{pH}_{3}=11\right.$, and $\left.\mathrm{pH}_{4}=10\right)$, four levels of alkalization temperature $\left(\mathrm{T}_{1}=30^{\circ} \mathrm{C}, \mathrm{T}_{2}=40^{\circ} \mathrm{C}, \mathrm{T}_{3}=50^{\circ} \mathrm{C}\right.$, and $\left.\mathrm{T}_{4}=60^{\circ} \mathrm{C}\right)$, four levels of alkalization duration $\left(\mathrm{t}_{1}=15\right.$ minutes, $\mathrm{t}_{2}=30$ minutes, $\mathrm{t}_{3}=60$ minutes, and $\mathrm{t}_{4}=120 \mathrm{~min}-$ utes), four levels of initial iron-ion concentration $\left(\mathrm{C}_{1}=400\right.$ $\mathrm{mM} \mathrm{FeCl}+200 \mathrm{mM} \mathrm{FeCl}_{2}, \mathrm{C}_{2}=200 \mathrm{mM} \mathrm{FeCl}_{3}+100 \mathrm{mM}$ $\mathrm{FeCl}_{2}, \mathrm{C}_{3}=100 \mathrm{mM} \mathrm{FeCl}_{3}+50 \mathrm{mM} \mathrm{FeCl}_{2}$, and $\mathrm{C}_{4}=50 \mathrm{mM}$ 


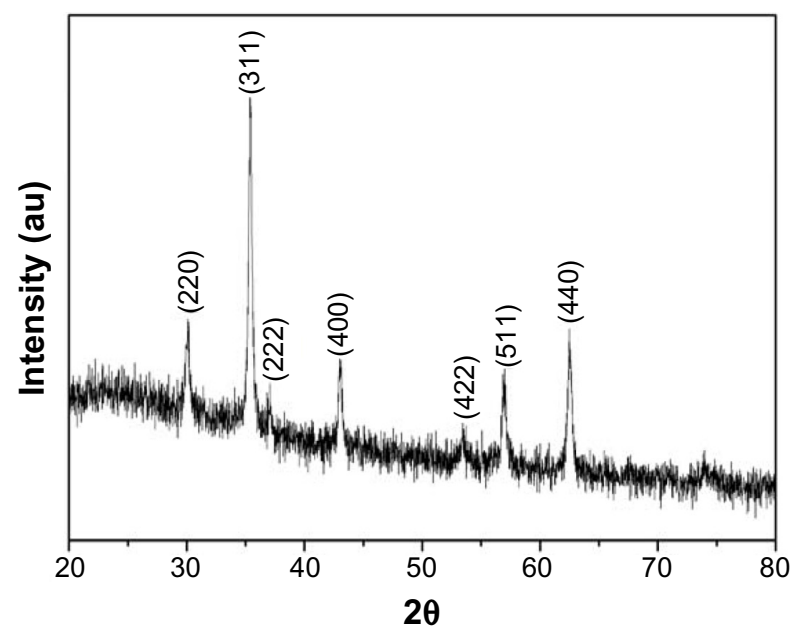

Figure I Power of the iron-oxide cores as determined by $\mathrm{X}$-ray powder diffraction. The peak used to determine the average particle size was at $2 \theta=35.65^{\circ}$ (Miller indices $\left.\left[\begin{array}{lll}3 & \mathrm{I} & \mathrm{l}\end{array}\right]\right)$.

$\mathrm{FeCl}_{3}+25 \mathrm{mM} \mathrm{FeCl}_{2}$ ) were studied individually. Then, an orthogonal experimental design $-\mathrm{L}_{16}\left(4^{5}\right)$ - was applied to determine the best composition of those experimental conditions.

The $\mathrm{pH}$ range of $10-13$ was chosen because moderate alkaline conditions would be suitable for ironion precipitation. High $\mathrm{pH}$ may cause vigorous lipid hydrolysis. The temperature range was chosen around the phase-transition temperature of DPPC, which might be the optimal temperature for getting a balance between lipid membrane permeability and liposome integrity. The alkalization duration range was chosen based on the common incubation time for drug loading by $\mathrm{pH}$ gradient. The iron-ion concentration range was chosen around $150 \mathrm{mM}$, which had a $\mathrm{pH}$ value of about 1 , as a higher concentration with a lower $\mathrm{pH}$ value would greatly intensify lipid hydrolysis.

\section{In vitro stability analysis}

The in vitro stability of the magnetoliposomes was assessed when they were stored at $4^{\circ} \mathrm{C}$ or $37^{\circ} \mathrm{C}$ for 3 months. For every week in the first month and every two weeks in the following two months, a $1 \mathrm{~mL}$ sample of the liposomes was drawn for size determination by dynamic light scattering and EE determination using the method described earlier in the "Characterization of magnetoliposomes" section.

\section{Results}

\section{Characterization of the iron-oxide cores}

The iron-oxide cores of magnetoliposomes were obtained by the method described earlier in the "Characterization of magnetoliposomes" section. The X-ray diffraction patterns of the iron-oxide cores confirmed the particles were single-phase cubic magnetite $\left(\mathrm{Fe}_{3} \mathrm{O}_{4}\right)$ (Figure 1). The room-temperature magnetization curves of the iron-oxide cores showed superparamagnetic response and the saturation magnetization value of $19.5 \mathrm{emu} / \mathrm{g}$ (Figure 2).

\section{Liposome size and morphology}

The magnetoliposomes were of brownish semitransparent appearance. The size, determined by dynamic light scattering and expressed as $z$-average, was $168 \pm 14 \mathrm{~nm}$ (polydispersity index $=0.23 \pm 0.06$; Figure 3 ) and the zeta potential was $-26.2 \pm 1.9 \mathrm{mV}(\mathrm{n}=3)$.

TEM micrographs of magnetoliposomes are presented in Figure 4. Figure 4A shows the liposome-encapsulated $\mathrm{FeCl}_{3} /$ $\mathrm{FeCl}_{2}$ solution before alkalization, while Figure 4B shows the liposomes after alkalization. Before alkalization, the liposomes were basically transparent. After alkalization, the liposomes became opaque with high-density areas scattered irregularly through them.

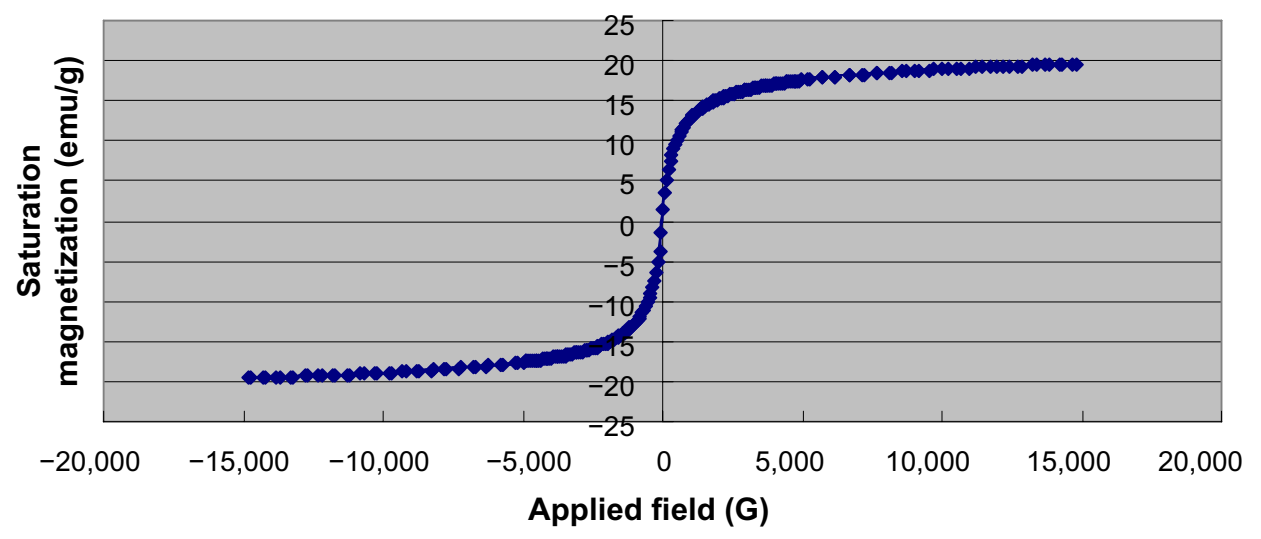

Figure 2 Magnetization curves of iron-oxide cores measured at room temperature. 
Size distribution by number

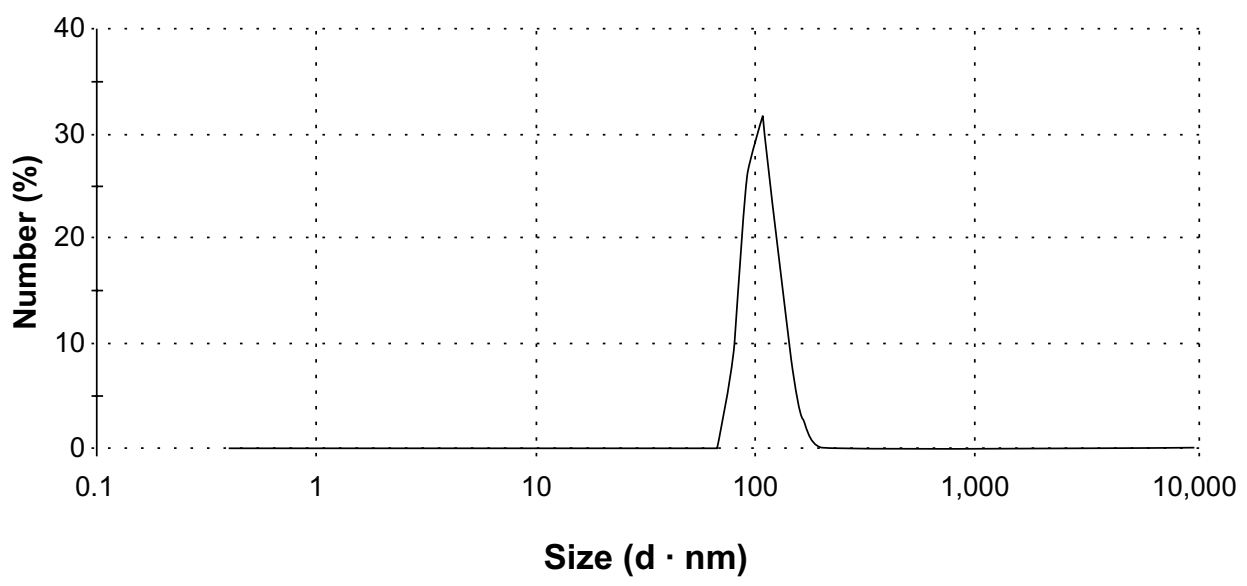

Figure 3 Size distribution of the magnetoliposomes by number.

\section{EE and drug loading}

The EE and drug loading were determined with varying initial iron-ion concentrations, alkalization $\mathrm{pHs}$, temperatures, and durations. The initial lipid concentration was $20 \mathrm{mM}$.

The EE ranged from $3 \%$ to $22 \%$, and the drug loading ranged from 0.2 to $1.58 \mathrm{~mol} \mathrm{Fe} / \mathrm{mol}$ lipid. Details are shown in Tables 1-4.

\section{Effects of alkalization $\mathrm{pH}$, temperature, duration, and initial Fe concentration}

Single-factor analysis was performed to determine the effect of alkalization $\mathrm{pH}$, temperature $(\mathrm{T})$, duration $(\mathrm{t})$, and initial iron-ion concentration (C) on the EE and drug loading of the magnetoliposomes. An orthogonal experimental design $-\mathrm{L}_{16}\left(4^{5}\right)$ - was applied to determine the best combination of experimental conditions.

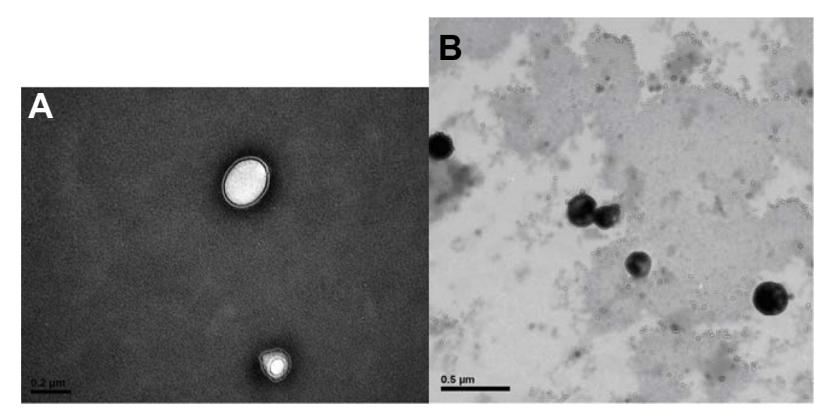

Figure 4 Transmission electron microscopy micrographs of negatively stained liposomes. (A) The liposome-encapsulated iron ions before alkalization; (B) the liposome-encapsulated iron ions after alkalization. Before alkalization, the liposomes were basically transparent. After alkalization, the liposomes became opaque with high-density areas scattered irregularly in the liposomes. Preparation conditions: $\mathrm{pH} \mathrm{I2}$, temperature $=60^{\circ} \mathrm{C}$, time $=60$ minutes, initial Fe concentration $=150 \mathrm{mM}$.

\section{Alkalization $\mathrm{pH}$}

Four levels of alkalization $\mathrm{pH}\left(\mathrm{pH}_{1}=10, \mathrm{pH}_{2}=11, \mathrm{pH}_{3}=12\right.$, and $\mathrm{pH}_{4}=13$ ) were applied to determine the effect of alkalization $\mathrm{pH}$. The values of initial iron-ion concentration (C), alkalization temperature $(\mathrm{T})$, and alkalization time $(\mathrm{t})$ were fixed at $\mathrm{C}=150$ $\mathrm{mM}, \mathrm{T}=50^{\circ} \mathrm{C}$, and $\mathrm{t}=30$ minutes according to the results of the preliminary study. The initial lipid concentration was $20 \mathrm{mM}$.

The EE and drug loading reached their maximum at $\mathrm{pH}$ 12. The total Fe concentrations in liposomes after alkalization $(\mathrm{Fe}[\mathrm{t}])$ were very close at $\mathrm{pH} 10-12$, but decreased significantly at $\mathrm{pH} 13$. The free iron-ion concentrations in the liposomes $(\mathrm{Fe}[\mathrm{f}])$ decreased significantly as the $\mathrm{pH}$ increased (as shown in Table 1 and Figure 5).

\section{Alkalization temperature}

Four levels of alkalization temperature $\left(\mathrm{T}_{1}=30^{\circ} \mathrm{C}, \mathrm{T}_{2}=40^{\circ} \mathrm{C}\right.$, $\mathrm{T}_{3}=50^{\circ} \mathrm{C}$, and $\mathrm{T}_{4}=60^{\circ} \mathrm{C}$ ) were applied to determine the effect of alkalization temperature. The values of initial iron-ion concentration $(\mathrm{C})$, alkalization $\mathrm{pH}$, and alkalization time $(\mathrm{t})$ were fixed at $\mathrm{C}=150 \mathrm{mM}, \mathrm{pH} 12, \mathrm{t}=30$ minutes according to the results of the preliminary study. The initial lipid concentration was $20 \mathrm{mM}$.

The drug loading increased as the alkalization temperature increased and reached its maximum at $60^{\circ} \mathrm{C}$, while the $\mathrm{EE}$ was not augmented further beyond $50^{\circ} \mathrm{C}$. Fe(t) decreased slightly as temperature increased, while $\mathrm{Fe}(\mathrm{f})$ decreased dramatically as the temperature increased (as shown in Table 2 and Figure 6).

\section{Alkalization duration \\ Four levels of alkalization duration $\left(t_{1}=15\right.$ minutes, $\mathrm{t}_{2}=30$ minutes, $\mathrm{t}_{3}=60$ minutes, and $\mathrm{t}_{4}=120$ minutes) were}


Table I Effect of alkalization $\mathrm{pH}$

\begin{tabular}{|c|c|c|c|c|c|c|c|}
\hline \multirow[t]{3}{*}{$\mathrm{pH}$} & \multicolumn{4}{|c|}{ Fe concentration $(\mathrm{mM})$} & \multirow{3}{*}{$\begin{array}{l}\text { Encapsulation } \\
\text { efficiency (\%) }\end{array}$} & \multirow{3}{*}{$\begin{array}{l}\text { Final lipid } \\
\text { content (mM) }\end{array}$} & \multirow{3}{*}{$\begin{array}{l}\text { Drug loading } \\
\text { (mol Fe/mol lipid) }\end{array}$} \\
\hline & \multirow{2}{*}{$\begin{array}{l}\text { Before alkalization } \\
\mathrm{Fe}_{\mathrm{b}}\end{array}$} & \multicolumn{3}{|c|}{ After alkalization } & & & \\
\hline & & $\mathrm{Fe}(\mathrm{t})$ & $\mathrm{Fe}(f)$ & $\mathrm{Fe}(\mathrm{c})$ & & & \\
\hline 13 & $34.2 \pm 0.5$ & $18.3 \pm 1.2$ & $1.5 \pm 0.8$ & $16.8 \pm 0.4$ & $1 \mathrm{I} .1 \pm 0.3$ & $18.1 \pm 0.4$ & $0.92 \pm 0.02$ \\
\hline 12 & $35.0 \pm 0.7$ & $30.8 \pm 1.8$ & $4.3 \pm 2.5$ & $26.5 \pm 1.2$ & $17.7 \pm 0.8$ & $19.1 \pm 0.4$ & $1.39 \pm 0.04$ \\
\hline 11 & $34.0 \pm 1.8$ & $30.9 \pm 1.3$ & $16.0 \pm 1.3$ & $14.9 \pm 0.5$ & $9.9 \pm 0.3$ & $19.1 \pm 0.4$ & $0.78 \pm 0.04$ \\
\hline 10 & $33.6 \pm 1.3$ & $30.4 \pm 0.8$ & $18.2 \pm 0.7$ & $12.1 \pm 0.5$ & $8.1 \pm 0.4$ & $19.2 \pm 0.3$ & $0.63 \pm 0.02$ \\
\hline
\end{tabular}

Note: $n=3$.

Abbreviations: $\mathrm{Fe}_{\mathrm{b}}$, the amount of iron ions in liposomes before alkalization; $\mathrm{Fe}(\mathrm{t})$, the amount of total iron in the liposomes after alkalization; Fe( $\left.\mathrm{f}\right)$, the amount of free iron ions in the liposomes after alkalization; $\mathrm{Fe}(\mathrm{c})$, the amount of iron-oxide cores in magnetoliposomes.

applied to determine the effect of alkalization duration. The values of initial iron-ion concentration (C), alkalization $\mathrm{pH}$, and alkalization temperature $(\mathrm{T})$ were fixed at $\mathrm{C}=150 \mathrm{mM}, \mathrm{pH} 12$, and $\mathrm{T}=60^{\circ} \mathrm{C}$ according to the results of the preliminary study. The initial lipid concentration was $20 \mathrm{mM}$.

The EE and drug loading were increased as alkalization duration lengthened and reached a maximum at 60 minutes. The Fe(t) decreased slightly with longer alkalization duration, while the $\mathrm{Fe}(\mathrm{f})$ markedly decreased at 30 minutes, then remained at almost the same level after that (as shown in Table 3 and Figure 7).

\section{Initial iron-ion concentration}

Four levels of initial iron-ion concentration $\left(\mathrm{C}_{1}=400 \mathrm{mM}\right.$ $\mathrm{FeCl}_{3}+200 \mathrm{mMFeCl}_{2}, \mathrm{C}_{2}=200 \mathrm{mMFeCl}_{3}+100 \mathrm{mMFeCl}_{2}, \mathrm{C}_{3}=100$ $\mathrm{mMFeCl}_{3}+50 \mathrm{mMFeCl}_{2}$, and $\mathrm{C}_{4}=50 \mathrm{mMFeCl}_{3}+25 \mathrm{mMFeCl}_{2}$ ) were applied to determine the effect of ionic concentration. The values of alkalization $\mathrm{pH}$, alkalization temperature (T), and alkalization time (t) were fixed at $\mathrm{pH} 12, \mathrm{~T}=60^{\circ} \mathrm{C}$, $\mathrm{t}=60$ minutes, according to the results of the preliminary study. The initial lipid concentration was $20 \mathrm{mM}$.

With the decrease of the initial iron-ion concentration, the EE increased gradually, while the drug loading reached maximum at an initial Fe concentration of $150 \mathrm{mM}$ (as shown in Table 4 and Figure 8).

\section{Orthogonal experimental design}

An orthogonal experiment $-\mathrm{L}_{16}\left(4^{5}\right)$ - was applied to explore the optimal formulation with drug loading as the index. The detailed orthogonal experiment and related results are listed in Tables 5 and 6, respectively. Specifically, factor A, alkalization $\mathrm{pH}$; factor $\mathrm{B}$, initial Fe concentration; factor $\mathrm{C}$, alkalization temperature; factor $\mathrm{D}$, alkalization duration; factor $\mathrm{E}$, random (control factor). Each factor had four levels as indicated in Table 5. As determined by variance $R$ analysis, the order of influence for drug loading was found to be $\mathrm{A}>\mathrm{B}>\mathrm{C}>\mathrm{D}$. The best combination level of the four factors was A3B2C4D3. Therefore the optimum preparation conditions were: an initial Fe concentration of $150 \mathrm{mM}$, an alkalization $\mathrm{pH}$ of 12 , a temperature of $60^{\circ} \mathrm{C}$, and an alkalization duration of 60 minutes. The average drug loading of magnetoliposomes prepared with the optimal formulation was $1.58 \pm 0.04 \mathrm{~mol} \mathrm{Fe} / \mathrm{mol}$ lipid (n=3).

\section{In vitro stability}

The magnetoliposomes prepared at $\mathrm{pH} 12, \mathrm{~T}=60^{\circ} \mathrm{C}$, $\mathrm{t}=60$ minutes, and $\mathrm{C}=150 \mathrm{mM}$ were stored at $4^{\circ} \mathrm{C}$ or $37^{\circ} \mathrm{C}$ for three months. The size of magnetoliposomes did not undergo significant changes for almost 4 weeks at $4^{\circ} \mathrm{C}$ and 3 weeks at $37^{\circ} \mathrm{C}$. After that, the size of the magnetoliposomes decreased gradually and the appearance gradually changed

Table 2 Effect of alkalization temperature

\begin{tabular}{|c|c|c|c|c|c|c|c|}
\hline \multirow[t]{3}{*}{$\mathrm{T}\left({ }^{\circ} \mathrm{C}\right)$} & \multicolumn{4}{|c|}{ Fe concentration $(\mathrm{mM})$} & \multirow{3}{*}{$\begin{array}{l}\text { Encapsulation } \\
\text { efficiency (\%) }\end{array}$} & \multirow{3}{*}{$\begin{array}{l}\text { Final lipid } \\
\text { content (mM) }\end{array}$} & \multirow{3}{*}{$\begin{array}{l}\text { Drug loading } \\
\text { (mol Fe/mol lipid) }\end{array}$} \\
\hline & \multirow{2}{*}{$\begin{array}{l}\text { Before alkalization } \\
\mathrm{Fe}_{\mathrm{b}}\end{array}$} & \multicolumn{3}{|c|}{ After alkalization } & & & \\
\hline & & $\mathrm{Fe}(\mathrm{t})$ & $\mathrm{Fe}(\mathbf{f})$ & $\mathrm{Fe}(\mathrm{c})$ & & & \\
\hline 30 & $35.2 \pm 0.8$ & $32.0 \pm 1.5$ & $17.9 \pm 1.0$ & $14.2 \pm 0.5$ & $9.4 \pm 0.3$ & $19.5 \pm 0.3$ & $0.73 \pm 0.03$ \\
\hline 40 & $34.5 \pm 0.5$ & $31.3 \pm 0.9$ & $\mid \mathrm{I} .5 \pm \mathrm{I} . \mathrm{I}$ & $19.8 \pm 0.4$ & $13.2 \pm 0.3$ & $19.1 \pm 0.3$ & $1.03 \pm 0.03$ \\
\hline 50 & $35.0 \pm 0.7$ & $30.8 \pm 1.8$ & $4.3 \pm 2.5$ & $26.5 \pm 1.2$ & $17.7 \pm 0.8$ & $19.1 \pm 0.4$ & $1.39 \pm 0.04$ \\
\hline 60 & $34.3 \pm 0.6$ & $29.7 \pm 0.4$ & $3.1 \pm 0.5$ & $26.6 \pm 0.6$ & $17.7 \pm 0.4$ & $18.2 \pm 0.3$ & $1.46 \pm 0.04$ \\
\hline
\end{tabular}

Note: $\mathrm{n}=3$.

Abbreviations: $\mathrm{Fe}_{\mathrm{b}}$, the amount of iron ions in liposomes before alkalization; $\mathrm{Fe}(\mathrm{t})$, the amount of total iron in the liposomes after alkalization; Fe( $\left.\mathrm{f}\right)$, the amount of free iron ions in the liposomes after alkalization; $\mathrm{Fe}(\mathrm{c})$, the amount of iron-oxide cores in magnetoliposomes; $\mathrm{T}$, temperature. 
Table 3 Effect of alkalization duration

\begin{tabular}{|c|c|c|c|c|c|c|c|}
\hline \multirow[t]{3}{*}{$\mathbf{T}$ (minutes) } & \multicolumn{4}{|c|}{ Fe concentration (mM) } & \multirow{3}{*}{$\begin{array}{l}\text { Encapsulation } \\
\text { efficiency (\%) }\end{array}$} & \multirow{3}{*}{$\begin{array}{l}\text { Final lipid } \\
\text { content (mM) }\end{array}$} & \multirow{3}{*}{$\begin{array}{l}\text { Drug loading } \\
\text { (mol Fe/mol lipid) }\end{array}$} \\
\hline & \multirow{2}{*}{$\begin{array}{l}\text { Before alkalization } \\
\mathrm{Fe}_{\mathrm{b}}\end{array}$} & \multicolumn{3}{|c|}{ After alkalization } & & & \\
\hline & & $\mathrm{Fe}(\mathrm{t})$ & $\mathrm{Fe}(\mathrm{f})$ & $\mathrm{Fe}(\mathrm{c})$ & & & \\
\hline 15 & $34.4 \pm 0.4$ & $30.5 \pm 0.8$ & $\mid I . I \pm I .1$ & $19.4 \pm 0.3$ & $12.9 \pm 0.2$ & $18.4 \pm 0.5$ & $1.05 \pm 0.04$ \\
\hline 30 & $34.3 \pm 0.6$ & $29.7 \pm 0.4$ & $3.1 \pm 0.5$ & $26.6 \pm 0.6$ & $17.7 \pm 0.4$ & $18.2 \pm 0.3$ & $1.46 \pm 0.04$ \\
\hline 60 & $34.6 \pm 0.6$ & $28.5 \pm 0.5$ & $0.8 \pm 0.2$ & $27.7 \pm 0.4$ & $18.5 \pm 0.3$ & $17.5 \pm 0.6$ & $1.58 \pm 0.04$ \\
\hline 120 & $34.2 \pm 0.4$ & $26.0 \pm 0.5$ & $1.0 \pm 0.3$ & $25.1 \pm 0.4$ & $16.7 \pm 0.3$ & $17.1 \pm 0.2$ & $1.46 \pm 0.04$ \\
\hline
\end{tabular}

Note: $n=3$.

Abbreviations: $\mathrm{Fe}_{\mathrm{b}}$, the amount of iron ions in liposomes before alkalization; $\mathrm{Fe}(\mathrm{t})$, the amount of total iron in the liposomes after alkalization; Fe(f), the amount of free iron ions in the liposomes after alkalization; $\mathrm{Fe}(\mathrm{c})$, the amount of iron-oxide cores in magnetoliposomes; $\mathrm{T}$, time.

from semitransparent to turbid. The EE underwent similar changes (Figure 9).

\section{Discussion}

In this study, we developed a novel approach for the preparation of magnetoliposomes. Unlike other methods commonly used in other studies, the new method eliminated the demand for magnetofluid preparation, while the magnetic cores were formed in situ within the liposomes. The theoretical basis for this novel method is that different substances have different abilities to diffuse through the phospholipids bilayer, with small molecules, such as $\mathrm{NH}_{3}$, having a significantly greater permeability coefficient $\left(10^{-2} \mathrm{~cm} / \mathrm{s}\right)$ than ions, such as $\mathrm{Fe}^{3+} / \mathrm{Fe}^{2+}\left(10^{-13} \mathrm{~cm} / \mathrm{s}\right) .{ }^{8-10}$ Accordingly, $\mathrm{FeCl}_{3} / \mathrm{FeCl}_{2}$ solutions were first encapsulated into the inner aqueous phase of liposome, then $\mathrm{NH}_{3} \cdot \mathrm{H}_{2} \mathrm{O}$ was added into the external phase. The $\mathrm{NH}_{3}$ molecules rapidly diffused into the liposomes under the concentration gradient force, while only few $\mathrm{Fe}^{3+} /$ $\mathrm{Fe}^{2+}$ ions leaked out from the liposomes because of their low permeability coefficient. With the accumulation of $\mathrm{NH}_{3}$ in the inner phase, the $\mathrm{pH}$ value increased gradually. Finally the $\mathrm{Fe}^{3+} / \mathrm{Fe}^{2+}$ were hydrolyzed and precipitated as iron oxides in an alkaline environment. The schematic diagram of the in situ precipitation is shown in Figure 10.

Iron-oxide cores may form at one site, since the liposome membrane is not absolutely homogeneous due to hydrolysis, and a suitable site may act as a nucleation center. Once nucleation has begun and the critical nucleus size has been surpassed, this site will be more favorable than any other for the development of single crystals. The nucleation may also occur simultaneously at many sites if multiple nucleation centers exist on the membrane. So, the distribution of crystal cores would be rather irregular, as seen in Figure 4.

\section{Major advantages of this new method}

The method provides a simple and easy option for magnetoliposome preparation that does not require magnetofluid to be prepared, while its drug loading is close to that of the conventional approach. The process of magnetofluid preparation is usually complicated and laborious. In addition, magnetofluid is usually unstable and tends to aggregate and settle down during the preparation process of magnetoliposomes, leading to the low EE of magnetofluid in liposomes. The EE of magnetoliposomes prepared by a conventional method ranges between $2 \%$ and $12 \%,{ }^{4,6}$ while a high EE of $22 \%$ was achieved by our new method. Although the EE decreased with the increase of initial Fe concentration in our study, the maximal drug loading ( $1.58 \mathrm{~mol} \mathrm{Fe} / \mathrm{mol}$ lipid) achieved was close to the reported maximal value (1.67 mol Fe/mol lipid). ${ }^{4}$

Another potential advantage of this novel approach is that it may be useful in preparing magnetoliposomes

Table 4 Effect of initial iron-ion concentration

\begin{tabular}{|c|c|c|c|c|c|c|c|}
\hline \multirow[t]{3}{*}{$\mathrm{Fe}_{\mathrm{a}}(\mathrm{mM})$} & \multicolumn{4}{|c|}{ Fe concentration (mM) } & \multirow{3}{*}{$\begin{array}{l}\text { Encapsulation } \\
\text { efficiency (\%) }\end{array}$} & \multirow{3}{*}{$\begin{array}{l}\text { Final lipid } \\
\text { content (mM) }\end{array}$} & \multirow{3}{*}{$\begin{array}{l}\text { Drug loading } \\
\text { (mol Fe/mol lipid) }\end{array}$} \\
\hline & \multirow{2}{*}{$\begin{array}{l}\text { Before alkalization } \\
\mathrm{Fe}_{\mathrm{b}}\end{array}$} & \multicolumn{3}{|c|}{ After alkalization } & & & \\
\hline & & $\mathrm{Fe}(\mathrm{t})$ & $\mathrm{Fe}(f)$ & $\mathrm{Fe}(\mathrm{c})$ & & & \\
\hline 600 & $37.6 \pm 2.7$ & $19.4 \pm 2.1$ & $1.2 \pm 0.6$ & $18.2 \pm 1.5$ & $3.0 \pm 0.3$ & $16.0 \pm 0.2$ & $1.14 \pm 0.09$ \\
\hline 300 & $35.5 \pm 1.1$ & $21.6 \pm 1.1$ & $1.2 \pm 0.3$ & $20.4 \pm 1.0$ & $6.8 \pm 0.3$ & $16.9 \pm 0.2$ & $1.21 \pm 0.05$ \\
\hline 150 & $34.6 \pm 0.6$ & $28.5 \pm 0.5$ & $0.8 \pm 0.2$ & $27.7 \pm 0.4$ & $18.5 \pm 0.3$ & $17.5 \pm 0.6$ & $1.58 \pm 0.04$ \\
\hline 75 & $17.9 \pm 0.4$ & $16.9 \pm 0.3$ & $0.2 \pm 0.1$ & $16.8 \pm 0.4$ & $22.3 \pm 0.5$ & $18.7 \pm 0.2$ & $0.90 \pm 0.01$ \\
\hline
\end{tabular}

Note: $\mathrm{n}=3$.

Abbreviations: $\mathrm{Fe}_{\mathrm{a}}$, the initial concentration of iron ions added in the system; $\mathrm{Fe}_{\mathrm{b}}$, the amount of iron ions in liposomes before alkalization; Fe(t), the amount of total iron in the liposomes after alkalization; $\mathrm{Fe}(\mathrm{f})$, the amount of free iron ions in the liposomes after alkalization; $\mathrm{Fe}(\mathrm{c})$, the amount of iron-oxide cores in magnetoliposomes. 
The effect of alkalization $\mathrm{pH}$

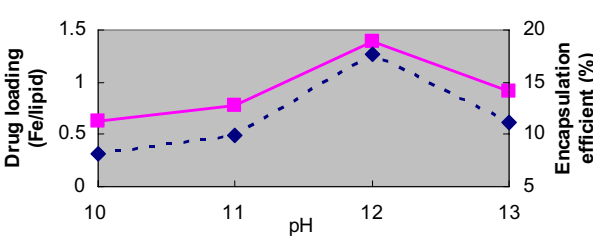

$\longrightarrow$ Drug loading $\quad-\bullet-$ Encapsulation efficiency
The effect of alkalization $\mathrm{pH}$

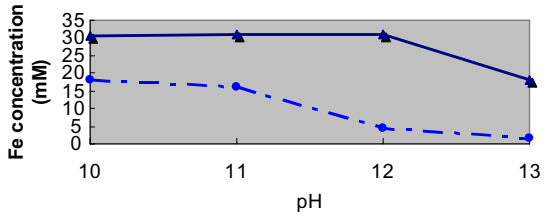

$\longrightarrow \mathrm{Fe}(\mathrm{t})-\bullet-\mathrm{Fe}(\mathrm{f})$

Figure $\mathbf{5}$ The effect of alkalization $\mathrm{pH}$.

Abbreviations: $\mathrm{Fe}(\mathrm{t})$, the amount of total iron in the liposomes after alkalization; $\mathrm{Fe}(\mathrm{f})$, the amount of free iron ions in the liposomes after alkalization.
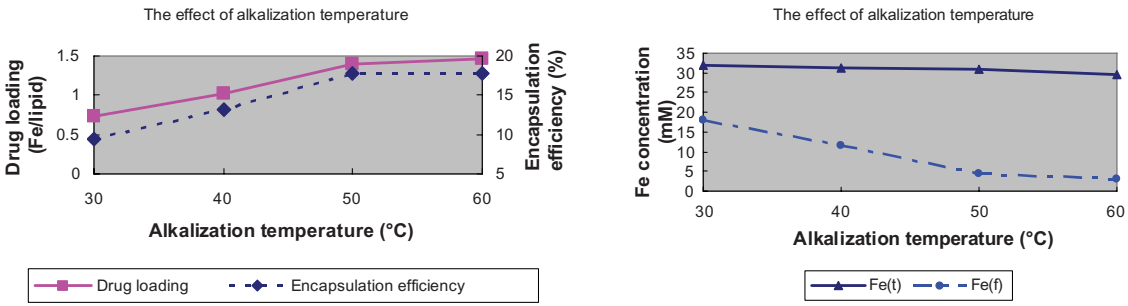

Figure 6 The effect of alkalization temperature.

Abbreviations: $\mathrm{Fe}(\mathrm{t})$, the amount of total iron in the liposomes after alkalization; $\mathrm{Fe}(\mathrm{f})$, the amount of free iron ions in the liposomes after alkalization.
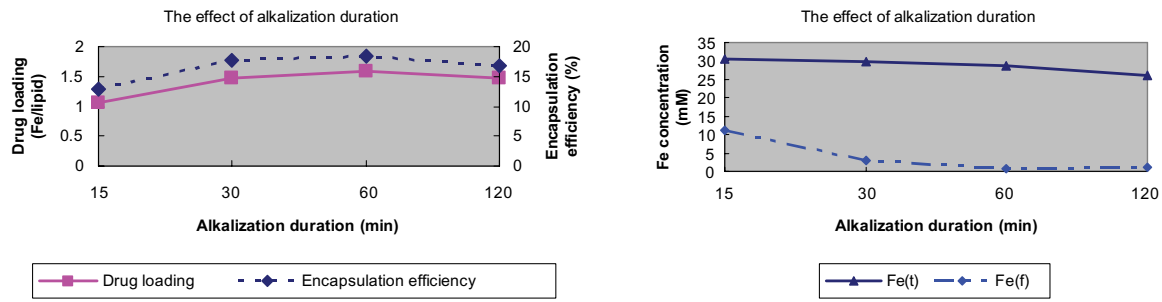

Figure 7 The effect of alkalization duration.

Abbreviations: $\mathrm{Fe}(\mathrm{t})$, the amount of total iron in the liposomes after alkalization; $\mathrm{Fe}(\mathrm{f})$, the amount of free iron ions in the liposomes after alkalization.
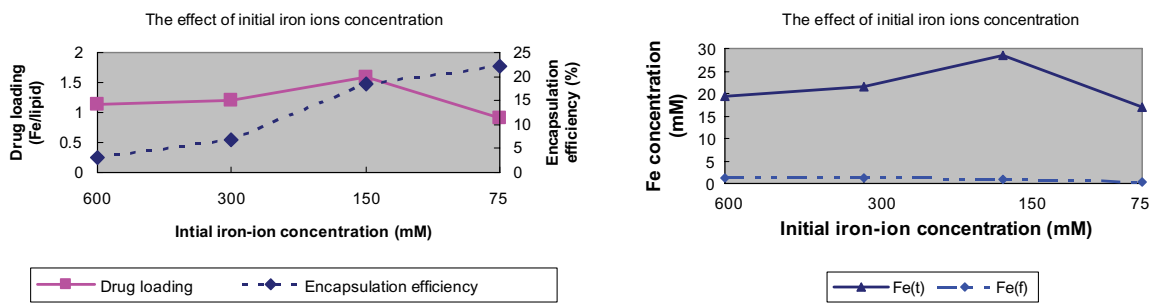

Figure 8 The effect of initial iron-ion concentration.

Abbreviations: $\mathrm{Fe}(\mathrm{t})$, the amount of total iron in the liposomes after alkalization; $\mathrm{Fe}(\mathrm{f})$, the amount of free iron ions in the liposomes after alkalization.

Table 5 Four levels of five factors in orthogonal experiments

\begin{tabular}{llllll}
\hline Level & Factor & & & \\
\cline { 2 - 6 } & $\begin{array}{l}\text { A: initial Fe } \\
\text { concentration }(\mathbf{m M})\end{array}$ & B: alkalization pH & $\begin{array}{l}\text { C: alkalization } \\
\text { temperature }\left({ }^{\circ} \mathbf{C}\right)\end{array}$ & $\begin{array}{l}\text { D: alkalization } \\
\text { duration (minutes) }\end{array}$ \\
\hline 1 & 600 & 13 & 30 & 15 & E: random* \\
2 & 300 & 12 & 40 & 30 & 2 \\
3 & 150 & 11 & 50 & 60 & 3 \\
4 & 75 & 10 & 60 & 120 & 4 \\
\hline
\end{tabular}

Note: *Random is the control factor of orthogonal experiment. 
Table 6 Results of orthogonal experiments

\begin{tabular}{|c|c|c|c|c|c|c|}
\hline $\begin{array}{l}\text { Experiment } \\
\text { number }\end{array}$ & $\begin{array}{l}\text { A: initial Fe } \\
\text { concentration }(\mathrm{mM})\end{array}$ & B: alkalization pH & $\begin{array}{l}\text { C: alkalization } \\
\text { temperature }\left({ }^{\circ} \mathrm{C}\right)\end{array}$ & $\begin{array}{l}\text { D: alkalization } \\
\text { duration (minutes) }\end{array}$ & E: random* & $\begin{array}{l}\text { Drug loading } \\
\text { (mol Fe/mol lipid) }\end{array}$ \\
\hline I & 1 & 1 & 1 & 1 & 1 & 0.24 \\
\hline 2 & I & 2 & 2 & 2 & 2 & 0.95 \\
\hline 3 & I & 3 & 3 & 3 & 3 & 0.69 \\
\hline 4 & I & 4 & 4 & 4 & 4 & 0.12 \\
\hline 5 & 2 & I & 2 & 3 & 4 & 1.02 \\
\hline 6 & 2 & 2 & I & 4 & 3 & 0.94 \\
\hline 7 & 2 & 3 & 4 & I & 2 & 0.89 \\
\hline 8 & 2 & 4 & 3 & 2 & I & 0.51 \\
\hline 9 & 3 & I & 3 & 4 & 2 & 0.95 \\
\hline 10 & 3 & 2 & 4 & 3 & I & 1.58 \\
\hline 11 & 3 & 3 & I & 2 & 4 & 0.43 \\
\hline 12 & 3 & 4 & 2 & I & 3 & 0.58 \\
\hline 13 & 4 & 1 & 4 & 2 & 3 & 0.57 \\
\hline 14 & 4 & 2 & 3 & I & 4 & 0.77 \\
\hline 15 & 4 & 3 & 2 & 4 & I & 0.48 \\
\hline 16 & 4 & 4 & 1 & 3 & 2 & 0.23 \\
\hline kl & 0.500 & 0.695 & 0.460 & 0.620 & 0.703 & \\
\hline k2 & 0.840 & 1.060 & 0.757 & 0.615 & 0.755 & \\
\hline k3 & 0.885 & 0.623 & 0.730 & 0.880 & 0.695 & \\
\hline k4 & 0.512 & 0.360 & 0.790 & 0.622 & 0.585 & \\
\hline $\mathrm{R}$ & 0.385 & 0.700 & 0.330 & 0.265 & 0.170 & \\
\hline
\end{tabular}

Note: *Random is the control factor of orthogonal experiment.

Abbreviations: $k$, the average drug-loading value of magnetoliposomes at different levels of every factor; $R$, the range of $k$ at different levels of every factor.

for loading insoluble compounds such as 5-Fluorouracil (5-FU). 5-FU is almost insoluble in water but shows good solubility in acidic solution. With $\mathrm{FeCl}_{3} / \mathrm{FeCl}_{2}$ solutions as hydrating mediums for lipid-film hydration, the new approach could significantly increase the drug loading of 5 -FU in magnetoliposomes. So, this new approach may provide a promising option to increase the drug loading of compounds with poor solubility in water but good solubility in acidic solutions.

\section{Disadvantage of the novel approach}

The disadvantage of this approach is the inevitable phospholipid hydrolysis that occurs during the preparation process. In an acidic or basic aqueous environment, phospholipid molecules are subjected to hydrolysis following pseudo first-order kinetics. ${ }^{11}$ The rate of hydrolysis depends on temperature and $\mathrm{pH}$, with a minimal rate at a $\mathrm{pH}$ of $6.5 .^{12,13}$ Accumulation of hydrolyzed products in the liposome membrane has been shown to alter the integrity of the bilayer and to induce leakage, fusion, and the transformation of liposomes into alternative aggregate structures. ${ }^{14}$ The hydrolysis rate and the influence of the hydrolyzed products on the liposome structure were not directly examined in this study, but the lipid content was determined at various conditions, which could be treated as an indirect index of phospholipid hydrolysis.

The lipid content decreased with the increase of initial Fe concentration (Table 4), because the $\mathrm{pH}$ value of the initial liposome formulation decreased dramatically with the increase of initial Fe concentration (eg, pH 1.66 at $\mathrm{Fe}=75 \mathrm{mM}$, pH 0.85 at $\mathrm{Fe}=150 \mathrm{mM}$ ). The excess hydro-
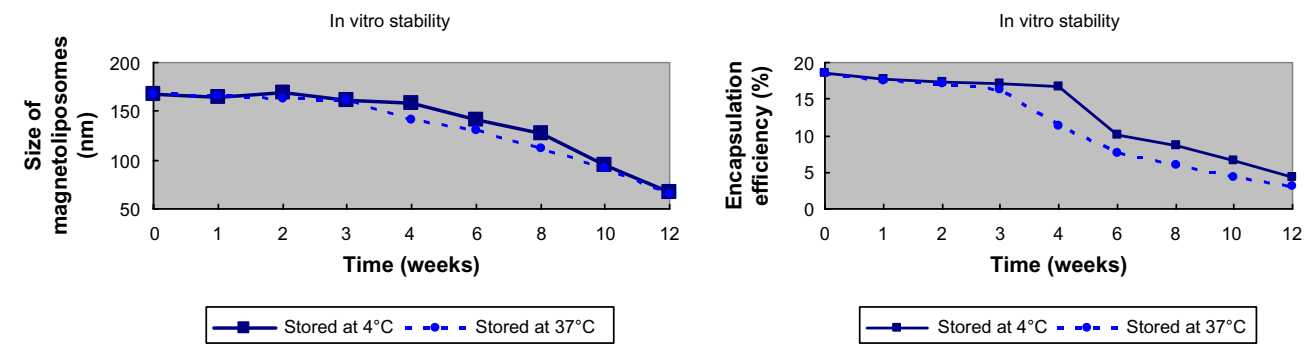

Figure 9 In vitro stability of magnetoliposomes. 


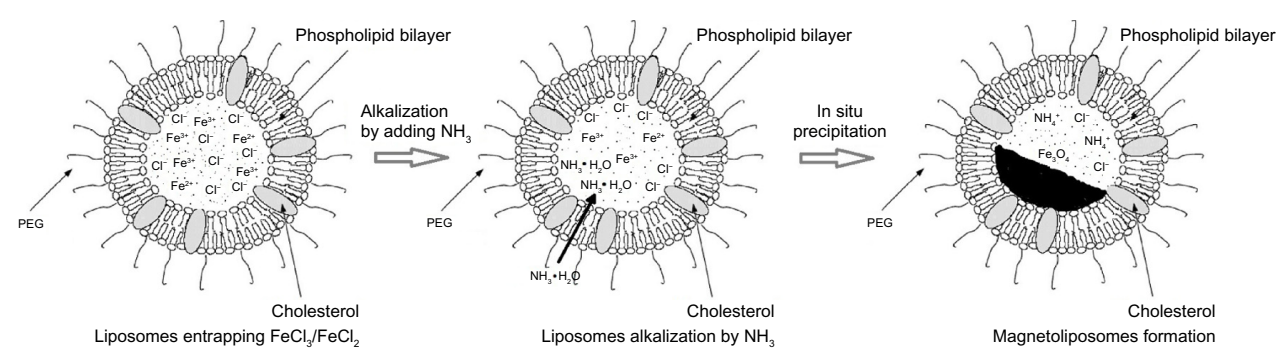

Figure 10 Possible mechanism of in situ precipitation within liposomes.

gen ions greatly catalyzed the lipid hydrolysis reaction and decreased the stability of the liposomes, therefore greatly decreased the EE of the liposomes (Table 4). In contrast, with the increase of the alkalization $\mathrm{pH}$, the lipid content decreased slightly (Table 1). This indicates that an excess amount of hydroxyl ions also catalyzed the hydrolysis reaction, although the effect of the hydroxyl ions was less profound than that of the hydrogen ions.

With the increase of alkalization temperature (Table 2) and alkalization duration (Table 3), the lipid content decreased slightly. This indicates that high temperature and long reaction duration accelerated the lipid hydrolysis reaction, although the effects of these were less profound than that of $\mathrm{pH}$ value.

\section{Predominant factors influencing the EE and drug loading of the novel methodology}

Alkalization $\mathrm{pH}$ had the most profound effect on the results. As $\mathrm{pH}$ increased, the amount of free iron ions in liposomes decreased greatly (Figure 5). This indicates that the increase in $\mathrm{pH}$ gradient between the outer and inner phases of the liposomes facilitated the influx of $\mathrm{NH}_{3}$. The critical $\mathrm{pH}$ point was 12; below this point, the majority of liposomes could not be alkalized. Increasing the $\mathrm{pH}$ value only slightly increased the extent of alkalization, but decreased the drug loading due to the increase in lipid hydrolysis.

Alkalization temperature and duration had similar influence on the results. Higher temperature led to a higher $\mathrm{NH}_{3}$ permeability coefficient and higher permeability of the lipid bilayer, which, on the one hand, facilitated the process of alkalization but, on the other, also enhanced the lipid hydrolysis rate. The critical point was $\mathrm{T}=50^{\circ} \mathrm{C}$; below this point, most liposomes could not be alkalized. Above this point, the $\mathrm{EE}$ and drug loading could not be enhanced further due to the increase in lipid hydrolysis (Figure 6). The critical point of alkalization duration was 30 minutes; below this point, most liposomes could not be alkalized. Above this point, the EE and drug loading increased slightly and reached maximum at 60 minutes (Figure 7).

\section{Effect of initial Fe concentration}

This has been discussed earlier. A higher initial Fe concentration led to stronger acidic conditions and more severe lipid hydrolysis. When the initial Fe concentration was greater than $150 \mathrm{mM}$, the EE decreased significantly.

\section{Other critical factors}

Aside from $\mathrm{pH}$, temperature, duration, and initial Fe concentration, the traditional critical factors of liposome preparation such as lipid composition and ultrasound parameters were not evaluated in this study because these factors were less involved in the alkalization process and their effects on EE and drug loading have already been well elucidated in conventional liposome preparation.

Concerning the lipid composition, saturated phospholipids such as DPPC would be more suitable for this novel magnetoliposome-preparation approach than unsaturated phospholipids, since unsaturated phospholipids are more easily oxidized by iron ions. A high molar percent of $\mathrm{CH}$ (>30\%) may be also critical to the success of in situ precipitation, since liposomes with a high $\mathrm{CH}$ percentage are more stable and have a broader range of liquid crystal transition temperatures. ${ }^{15}$

\section{Future directions}

To increase the drug loading and stability of magnetoliposomes prepared by in situ precipitation, further research is needed on the prevention of lipid hydrolysis. The possible resolutions include switching $\mathrm{FeCl}_{3} / \mathrm{FeCl}_{2}$ solutions with a less acidic agent such as pure $\mathrm{FeCl}_{2}$ solution or ferric ammonium citrate solution, adding a lipid-hydrolysis protective agent, and dissolving the $\mathrm{FeCl}_{3} / \mathrm{FeCl}_{2}$ compound in an amphiphilic solvent.

\section{Conclusion}

In this study, we developed a novel approach (in situ precipitation) for iron-oxide magnetoliposome preparation. We investigated the physical and chemical properties of magnetoliposomes prepared by this new method and also evaluated 
the critical factors influencing the EE and drug loading of magnetoliposomes. Taken together, our findings indicate we have established a simple and efficient approach for the preparation of iron-oxide magnetoliposomes.

\section{Acknowledgments}

We greatly appreciated the help of Professor Ying Xiaoying (Zhejiang University College of Pharmacy) for liposome preparation, Wu Jian (Zhejiang University College of Nanotechnology) for the TEM micrographs, Jin Lifen (Zhejiang University College of Medicine) for the atomic absorption spectroscopy, and Armah Malik (Zhejiang University College of Medicine) for checking of English.

This work was supported by the NSF of the People's Republic of China (Grant No 30900613), funds from the Science Technology Department of Zhejiang Province (Grant No N20130610), and the International Collaboration Project of Science and Technology Department of Zhejiang Province (Grant No 2011C14027).

\section{Disclosure}

The authors declare no conflicts of interest in this work.

\section{References}

1. Bakandritsos A, Fatourou AG, Fatouros DG. Magnetoliposomes and their potential in the intelligent drug-delivery field. Ther Deliv. 2012;3(12):1469-1482.

2. Li S, Zheng J, Chen D, et al. Yolk-shell hybrid nanoparticles with magnetic and $\mathrm{pH}$-sensitive properties for controlled anticancer drug delivery. Nanoscale. 2013;5(23):11718-11724.

3. Fattahi H, Laurent S, Liu F, Arsalani N, Vander Elst L, Muller RN. Magnetoliposomes as multimodal contrast agents for molecular imaging and cancer nanotheragnostics. Nanomedicine (Lond). 2011;6(3): $529-544$.
4. Martina MS, Fortin JP, Ménager C, et al. Generation of superparamagnetic liposomes revealed as highly efficient MRI contrast agents for in vivo imaging. J Am Chem Soc. 2005;127(30):10676-10685.

5. Sabaté R, Barnadas-Rodríguez R, Callejas-Fernández J, HidalgoAlvarez R, Estelrich J. Preparation and characterization of extruded magnetoliposomes. Int J Pharm. 2008;347(1-2):156-162.

6. Skouras A, Mourtas S, Markoutsa E, et al. Magnetoliposomes with high USPIO entrapping efficiency, stability and magnetic properties. Nanomedicine. 2011;7(5):572-579.

7. Lande MB, Donovan JM, Zeidel ML. The relationship between membrane fluidity and permeabilities to water, solutes, ammonia, and protons. J Gen Physiol. 1995;106(1):67-84.

8. Deamer DW, Bramhall J. Permeability of lipid bilayers to water and ionic solutes. Chem Phys Lipids. 1986;40(2-4):167-188.

9. Paula S, Volkov AG, Van Hoek AN, Haines TH, Deamer DW. Permeation of protons, potassium ions, and small polar molecules through phospholipid bilayers as a function of membrane thickness. Biophys $J$. 1996;70(1):339-348.

10. Leontiadou H, Mark AE, Marrink SJ. Ion transport across transmembrane pores. Biophys J. 2007;92(12):4209-4215.

11. Grit M, Underberg WJ, Crommelin DJ. Hydrolysis of saturated soybean phosphatidylcholine in aqueous liposome dispersions. J Pharm Sci. 1993;82(4):362-366.

12. Zhang JA, Pawelchak J. Effect of $\mathrm{pH}$, ionic strength and oxygen burden on the chemical stability of EPC/cholesterol liposomes under accelerated conditions. Part 1: Lipid hydrolysis. Eur J Pharm Biopharm. 2000;50(3):357-364.

13. Ickenstein LM, Sandström MC, Mayer LD, Edwards K. Effects of phospholipid hydrolysis on the aggregate structure in DPPC/DSPEPEG2000 liposome preparations after gel to liquid crystalline phase transition. Biochim Biophys Acta. 2006;1758(2):171-180.

14. Ickenstein LM, Sandström MC, Mayer LD, Edwards K. Effects of phospholipid hydrolysis on the aggregate structure in DPPC/DSPEPEG2000 liposome preparations after gel to liquid crystalline phase transition. Biochim Biophys Acta. 2006;1758(2):171-180.

15. Singer MA, Finegold L. Cholesterol interacts with all of the lipid in bilayer membranes. Implications for models. Biophys J. 1990;57(1): $153-156$.
International Journal of Nanomedicine

\section{Publish your work in this journal}

The International Journal of Nanomedicine is an international, peerreviewed journal focusing on the application of nanotechnology in diagnostics, therapeutics, and drug delivery systems throughout the biomedical field. This journal is indexed on PubMed Central, MedLine, CAS, SciSearch ${ }^{\circledR}$, Current Contents ${ }^{\circledR} /$ Clinical Medicine,

\section{Dovepress}

Journal Citation Reports/Science Edition, EMBase, Scopus and the Elsevier Bibliographic databases. The manuscript management system is completely online and includes a very quick and fair peer-review system, which is all easy to use. Visit http://www.dovepress.com/ testimonials.php to read real quotes from published authors. 